\title{
Analgesic Mechanism of Neurotropin: Relation to the Serotonergic System and Influence of Spinal Cord Transection
}

\author{
Eiji ITOH and Taeko HATA \\ Department of Pharmacology. Faculty of Pharmacy, Kinki University, \\ Kowakae, Higashi-Osaka 577. Japan \\ Accepted June 26, 1989
}

\begin{abstract}
Neurotropin, a nonprotein component extracted from the skin of rabbits treated with vaccinia virus, has been clinically and experimentally reported to demonstrate analgesic effects. In this study, we investigated the antinociceptive action of neurotropin in relation to the serotonergic system, a pain inhibitory system, and substance $P$, a pain transmitter; we also attempted to determine whether it acts at the spinal or supraspinal level in mice. 1) The spinal cord $\left(T_{6}-T_{10}\right)$ transection completely abolished the antinociceptive action of neurotropin, attenuated that of morphine, and had no influence on the action of clonidine. 2) The intrathecal substance $\mathrm{P}$-induced behavior was inhibited by $\left[\mathrm{D}\right.$-Pro ${ }^{2}, \mathrm{D}-\operatorname{Trp}^{7,9}$ ]-substance $\mathrm{P}$, but not by neurotropin. 3) Preadministration of $p$-chlorophenylalanine or cyproheptadine inhibited the antinociceptive action of neurotropin. These data suggest that neurotropin does not directly act on pain transmitters at the spinal cord level. but acts at the supraspinal level, resulting in an inhibition of pain transmitter release at the spinal level by mediating pain inhibitory systems such as the serotonergic system in addition to the noradrenergic and GABAergic systems previously reported.
\end{abstract}

Neurotropin, which is a nonprotein component extracted from the skin of rabbits treated with vaccinia virus, has been reported to show a more pronounced antinociceptive effect on diseased animals than on normal healthy animals, and it exerts strong antinociceptive effects on various types of hyperalgesic animals (1-3). Clinically, it is effectively used to treat severe pain in patients with lumbago, cervicodynia, SMON and various neuropathies (4-7). The analgesic effect of neurotropin on orthopedic pain is suggested to result, according to thermographic evaluation, from the improved peripheral blood flow (6). Also, we previously reported that the antinociceptive action of neurotropin differs in degree according to the administration route, and that its action appears to be non-opioid, and may be mediated by the noradrenergic and GABAergic systems (3).

In this report, we investigated whether the antinociceptive action of neurotropin originated in the spinal or supraspinal sites or both.
In addition, we examined whether neurotropin had a direct antagonistic action against substance $P$, a neurotransmitter for primary nociceptive afferent fibers, by observing the antagonistic action against the behavioral response in mice induced by intrathecal substance $P(8,9)$.

Next, we studied the antinociceptive action of neurotropin in relation to the serotonergic system, an important pain inhibitory system. We determined its effects by both the tail pressure and tail flick methods; this is because the system was reported to be very related to thermal stimuli (10).

\section{Materials and Methods}

Animals: Male ddY mice (Japan SLC. Inc., Shizuoka) weighing about $25 \mathrm{~g}$ were used.

Drug administration: Drugs were administered intracisternally, intrathecally or intraperitoneally.

Intracisternal (i.cist.) injection was carried out using a J-shaped needle (27 gauge) curved $40^{\circ}$ at $3.5 \mathrm{~mm}$ from the tip, according 
to the method of Ueda et al. (11). Each mouse was held by hand for this purpose. The needle was inserted into the cleft between the occiput and atlas vertebra through the intact skin. The injection volume was $10 \mu l$

Intrathecal (i.th.) injection was carried out by lumbar puncture, introducing the needle (30 gauge) into an intervertebral space approximately at the level of the 5 th or 6 th lumbar vertebrae, according to the method of Hylden and Wilcox (12). The drug solution was injected at a volume of $5 \mu l$.

Determination of antinociceptive effects: Nociceptive threshold was assessed by the tail-pressure and tail-flick methods.

The mechanical nociceptive threshold of mice was determined by the modified tailpressure method using a Randall-Selitto Analgesy-Meter (Ugo Basile). The force was applied to the tail at a point $1 \mathrm{~cm}$ distal from the root and increased at a constant rate of 16 $\mathrm{g} / \mathrm{sec}$. The force required to produce such reaction in the mouse as lifting, dropping or flexing its tail was defined as the nociceptive threshold.

The thermal nociceptive threshold of mice was quantified by the radiant heat method of D'Amour-Smith (13). Mice were subjected to the radiant heat of a $250 \mathrm{~W}$ tungsten lamp at the tip of their tail. The nociceptive threshold was defined as the latency (sec) of tail flexion. The lamp voltage was set to produce a pretreatment latency of approximately $10 \mathrm{sec}$.

These two types of methods were applied to both intact mice and spina! transected mice to determine the nociceptive threshold.

The antinociceptive effect of drugs was expressed as the antinociceptive index, which is the ratio of the nociceptive threshold after treatment to that before treatment. The antinociceptive action of neurotropin was observed twice at 45 and 60 min after i.p., 2 and 5 min after i.cist., and 5 and 8 min after i.th. administration: that of morphine and clonidine was observed twice at 30 and $45 \mathrm{~min}$ and at 15 and $30 \mathrm{~min}$ after the i.p. administration, respectively. In all cases, the mean of the two values were used as data.

Spinal cord $\left(\mathrm{T}_{6}-\mathrm{T}_{10}\right)$ transection: The mice were anesthetized with pentobarbital sodium (50 $\mathrm{mg} / \mathrm{kg}$, i.p., Abbott, Nembutal $\left.{ }^{\circledR}\right)$, and the spinal cord was severed at a point between the 6 th and 10 th thoracic vertebrae with a sharp safety razor according to the method of Zorn and Enna (14). Nociceptive threshold was examined 3 days after surgery.

Behavioral action of substance $P$ : The action of substance $P$ on mouse behavior was observed according to the method described by Hylden and Wilcox (9). The intensity of the action was quantified according to the total number of observed behaviors, consisting of bitings, lickings and scratchings of the abdomen and hind portion of the body, during a 2-min counting session from immediately after the injection, and the dose of substance $P$ used was $30 \mathrm{ng} / \mathrm{mouse}$, in accordance with our previous report (15).

Drugs: Neurotropin ${ }^{\infty}$ (Nippon Zoki. $20 \mathrm{mg}$ / $\mathrm{ml}), \mathrm{p}$-chlorophenylalanine methyl ester hydrochloride (PCPA, Sigma), cyproheptadine (Sigma), clonidine hydrochloride (Sigma), morphine hydrochloride (Takeda). substance $P$ (Peptide Institute Inc.) and [D-Pro ${ }^{2}$, DTrp ${ }^{7,9}$ ]-substance $P$ (Peptide Institute Inc.) were used, and these drugs were dissolved or diluted in $0.9 \%$ saline or pure water.

\section{Results}

1. Antinociceptive action of neurotropin in spinal transected mice: The antinociceptive actions of some i.p. administered drugs were observed in intact or spinal cord transected mice. These data are shown in Fig. 1. Clonidine showed similar antinociceptive action in spinal cord transected mice and in intact mice. The antinociceptive action of morphine was markedly attenuated by spinal cord transection, but its action was observed to remain dose-dependent. The antinociceptive action of neurotropin was abolished completely by spinal cord transection. These results were much the same in the tail-pressure method and in the tail-flick method.

2. No relation of neurotropin to substance $P$-induced behaviors was noted: Table 1 shows the total counts of behavioral responses induced by i.th. administration of 30 ng substance $P /$ mouse with and without neurotropin or $\left[D-P_{1}{ }^{2}, D-\operatorname{Trp}^{7,9}\right]$-substance $P$. When substance $P$ was coadministered with neurotropin, the count was much the same as the contral count. However, substance $\mathrm{P}$-induced behavior was inhibited by 
[D-Pro ${ }^{2}$, D-Trp ${ }^{7,9}$ ]-substance $P$, a substance $P$ antagonist; and the total count was significantly less than the control value. Neurotropin doses larger than $80 \mu \mathrm{g} /$ mouse were not examined in this experiment. because the administration volume was excessive for mice.

3. Influence of PCPA on the antinociceptive action of neurotropin: Figure 2 shows the

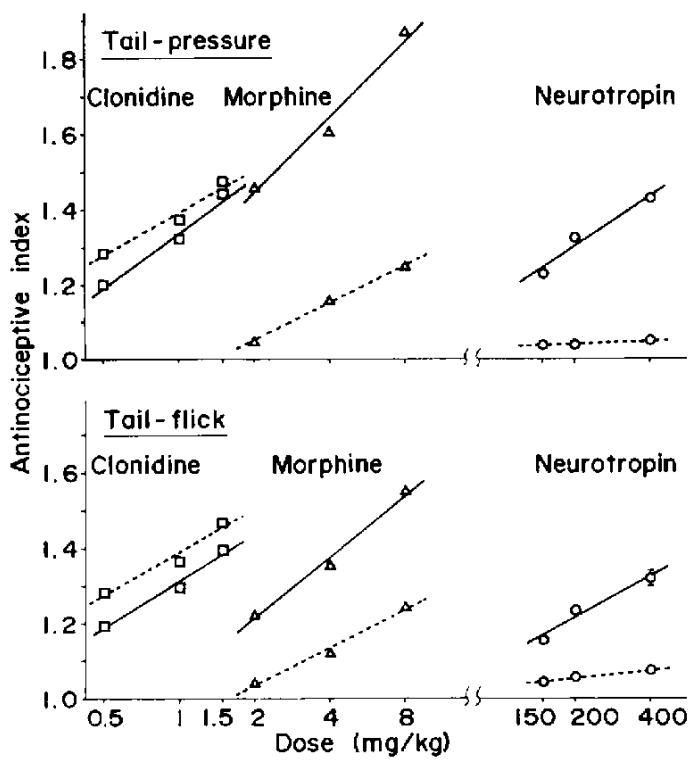

Fig. 1. Disappearance of the antinociceptive effect of neurotropin in spinal cord-transected mice. Intact mice, -----: trainsected mice. Nociception was measured 3 days after spinal cord transection. Predrug weight causing nociception (mean \pm S.E.) was $101.8 \pm 0.2 \mathrm{~g}$ (66 intact mice) or $91.1 \pm 0.3 \mathrm{~g}$ (62 transected mice), and pre-drug tail-flick latency (mean \pm S.E.) was $10.31 \pm 0.06 \mathrm{sec}$ (66 intact mice) or $9.14 \pm 0.05 \mathrm{sec}$ (62 transected mice). Each point represents the mean with S.E. value from 4-9 mice. Points only present means with S.E. values smailer than 0.0 ? antinociceptive action of neurotropin on the mice pretreated with PCPA, a serotonin depletor. The actions of neurotropin, 150 and $200 \mathrm{mg} / \mathrm{kg}$. were dose-dependently inhibited by 300 and $500 \mathrm{mg} / \mathrm{kg}$ of PCPA in both the tail-pressure method and the tail-flick method.

4. Influence of cyproheptadine on the antinociceptive action of neurotropin: Figure 3 shows the antinociceptive action of neurotropin on mice treated with cyproheptadine, a serotonin receptor blocker.

When neurotropin was simultaneously i.p. administered with cyproheptadine, its antinociceptive action decreased in a dosedependent manner by cyproheptadine. The antinociceptive index of i.cist. or i.th. neurotropin also decreased in a dose-dependent manner by cyproheptadine.

\section{Discussion}

In order to establish whether neurotropin acts directly at the spinal level or indirectly through acting at some supraspinal site, its action was examined as compared with the actions of morphine and clonidine in spinal cord $\left(T_{6}-T_{10}\right)$-transected mice. The spinal transection partially reduced the antinociceptive action of morphine, this in accordance with previous reports $(16,17)$ that morphine induces its antinociceptive action by acting at both supraspinal and spinal sites. The action of clonidine was not inhibited by the transection, in agreement with a previous report (18) that it induces an antinociceptive action by acting mostly at a spinal site. These data agree with the results of other investigators $(14,19$. 20) as well. On the other hand, the antinociceptive action of neurotropin was completely abolished by the spinal cord transection between $T_{6}$ and $T_{10}$. This fact suggests that

Table 1. Influence of neurotropin on substance P-induced behavior in mice

\begin{tabular}{|c|c|c|}
\hline Drug & & Response $/ 2 \min$ (count) \\
\hline Substance P & & $95.6 \pm 2.7$ \\
\hline Substance $P+$ Neurotropin & $40 \mu \mathrm{g} /$ mouse & $90.8 \pm 7.4$ \\
\hline Substance $P+$ Neurotropin & $80 \mu \mathrm{g} /$ mouse & $99.7 \pm 2.4$ \\
\hline Substance $P+D P D T$ & $800 \mathrm{ng} /$ mouse & $51.5 \pm 5.4^{* *}$ \\
\hline
\end{tabular}

DPDT: [D-Pro ${ }^{2}, D-\operatorname{Trp}^{7,9}$ ]-substance $P$. The response was quantified as the total number of observed lickings, bitings and scratchings. Neurotropin or DPDT was intrathecally coadministered with $30 \mathrm{ng}$ substance $P$ /mouse. Each value represents the mean with $S . E$. from 6 or 7 mice. ${ }^{* *} P<0.01$, from the group of substance P only (Newman-Keuls' test). 


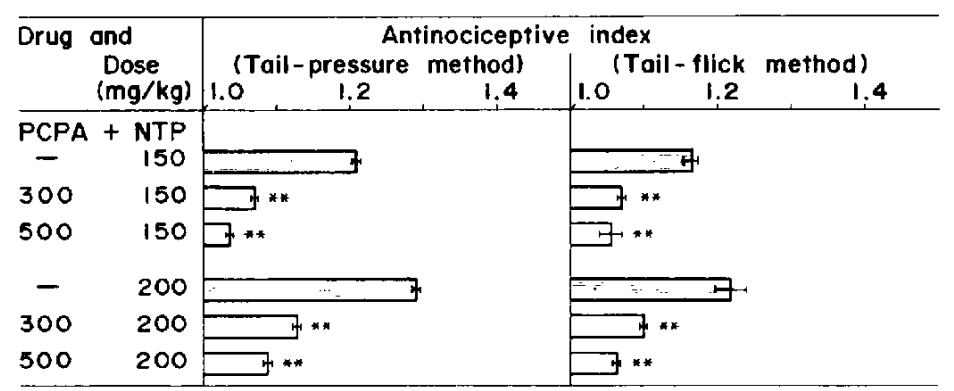

Fig. 2. Decrease in the antinociceptive effect of neurotropin (NTP) caused by p-chlorophenylalanine (PCPA). Antinociceptive index was the mean of two values determined at 45 and 60 min after i.p. NTP. PCPA was i.p. administered $23 \mathrm{hr}$ before NTP. Weight causing nociception before NTP (mean \pm S.E.) was $102.2 \pm 0.4 \mathrm{~g}$ (non-treatment). $101.7 \pm 0.5 \mathrm{~g}$ (23 hr after $300 \mathrm{mg} / \mathrm{kg}$ of PCPA) or $100.8 \pm 0.2 \mathrm{~g}$ (23 hr after $500 \mathrm{mg} / \mathrm{kg}$ of PCPA). Tail flick latency (mean \pm S.E.) before NTP was $10.48 \pm 0.04$ sec (nontreatment), $9.78 \pm 0.07 \mathrm{sec}(23 \mathrm{hr}$ after $300 \mathrm{mg} / \mathrm{kg}$ of PCPA) or $9.44 \pm 0.09 \mathrm{sec}(23 \mathrm{hr}$ after $500 \mathrm{mg} / \mathrm{kg}$ of PCPA). No. of mice: 4-6/group. ${ }^{* *} P<0.01$, from the respective control group treated with NTP only (Newman-Keuls' test).

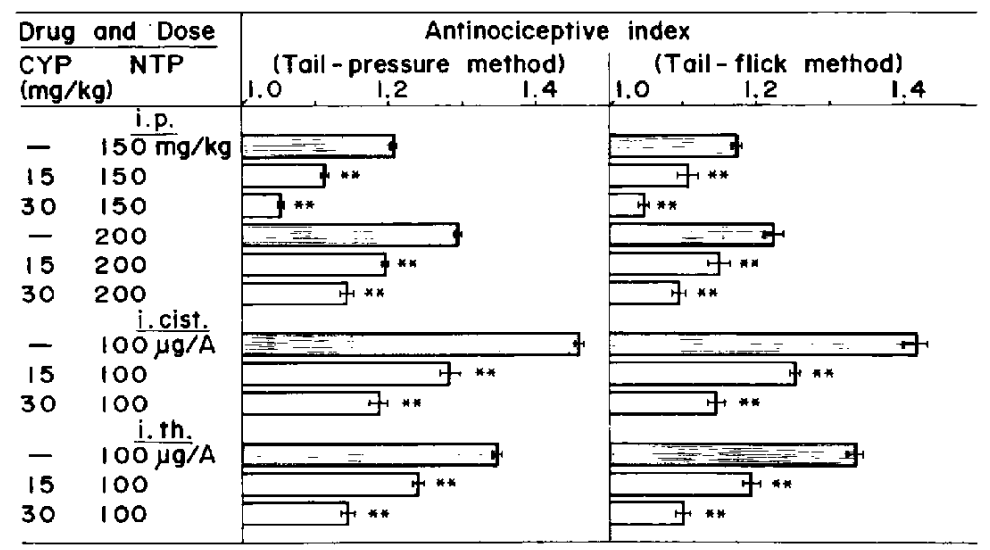

Fig. 3. Decrease in the antinociceptive action of neurotropin (NTP) caused by cyproheptadine (CYP). CYP was i.p. administered simultaneously with i.p. NTP or $10 \mathrm{~min}$ before i.cist. or i.th. NTP. Pre-drug weight causing nociception was $101.7 \pm 0.1 \mathrm{~g}(\mathrm{n}=74)$, and pre-drug tail-flick latency was $10.39 \pm 0.02 \mathrm{sec}$ $(n=72)$. No. of mice: $5-8 /$ group. ${ }^{* *} P<0.01$. from the respective control group treated with NTP only (Newman-Keuls' test).

neurotropin administered systemically exhibits its antinociceptive action by acting principally at a supraspinal site rostral to $T_{6}-T_{10}$.

In addition, neurotropin administered by the i.th. route also exhibited the antinociceptive action (Fig. 3). From this fact, it is thought that neurotropin may be able to directly inhibit the release of pain transmitters at the spinal site, if only it is able to reach the site. When neurotropin is systemically administered, however, it may be kept from reaching the spinal site by some barrier.

Neurotropin had no influence on i.th. sub- stance $\mathrm{P}$-induced behavioral response, which is accepted to be the result of noxious stimuli caused by substance $P(8,9)$. Namely. neurotropin exhibited the antinociceptive action on the nociception induced by the mechanical noxious stimuli, which were reported to cause release of substance $P$ in the spinal cord (21). but had no influence on the behavioral response induced by exogeous substance $P$ at the spinal level. In other words, neurotropin may not have a direct inhibitory action on substance $P$ or substance $P$ receptors in the spinal cord. 


\begin{tabular}{ll|ccc}
\hline Drugs & \multicolumn{3}{|c}{ Effect of neurotropin } \\
\cline { 3 - 5 } & Route & i.p. & i.cist. & i.th. \\
\hline Phentolamine & i.p. & $\downarrow$ & & \\
& $\begin{array}{l}\text { i.cist. } \\
\text { i.th. }\end{array}$ & & $\downarrow$ & $\downarrow$ \\
Reserpine & i.p. & $\downarrow$ & & \\
Cyproheptadine & i.p. & $\downarrow$ & $\downarrow$ & $\downarrow$ \\
p-Chlorophenylalanine & i.p. & $\downarrow$ & & \\
Atropine & i.p. & $\leftrightarrow$ & $\leftrightarrow$ & \\
Bicuculline & i.cist. & & $\downarrow$ & \\
Naloxone & i.p. & & $\leftrightarrow$ & \\
\hline
\end{tabular}

Fig. 4. A schema of influences of various drugs on the antinociceptive effect of neurotropin. $\quad \downarrow$ or $\leftrightarrow$ indicates decrease in the antinociceptive effect of neurotropin or no influence. Some of these data were quoted from Hata et al., Ref. No. 3.

The antinociceptive action of neurotropin was inhibited by PCPA, a serotonin depletor. and cyproheptadine, a serotonergic receptor blocker. From this, the action of neurotropin is thought to be related to the serotonergic system. The serotonergic system in pain inhibitory systems is reported to be more deeply related to thermal stimuli than to mechanical stimuli (10), but neurotropin showed antinociceptive action to a similar degree in the tail-pressure test, based on mechanical stimuli as well as in the tail-flick test, based on thermal stimuli: and its effect was similarly inhibited by PCPA or cyproheptadine in both tests. Furthermore, the effect of neurotropin administered by all of the i.p., i.cist. and i.th. routes was similarly inhibited by cyproheptadine. Then the antinociceptive action of neurotropin is thought to be related to the serotonergic system at either site of the supraspinal or spinal cord, so long as it reaches the site.

The influences of various drugs used in previous (3) and present studies on the antinociceptive action of neurotropin are summarized in Fig. 4. The antinociceptive action of neurotropine was inhibited by phentolamine, an $\alpha$-blocker; reserpine, a catecholamine depletor: cyproheptadine, a serotonin receptor blocker: PCPA, a serotonin depletor: and bicuculline, a $\mathrm{GABA}_{\mathrm{A}}$ antagonist; and not influenced by atropine, a muscarinic acetylcholine receptor blocker, or naloxone, an opiate antagonist. These data suggest that the antinociceptive action of neurotropin may be related to all of the serotonergic, noradrenergic and GABAergic systems, rather than to only one of these systems.

In summary, it is suggested that neurotropin has no direct inhibitory action on the action or receptor of pain transmitter at the spinal cord, but instead that it, administered systemically. may act at some supraspinal site, resulting in an inhibition of the release of pain transmitters at the spinal site by mediating descending pain inhibitory systems such as the serotonergic, noradrenergic and GABAergic systems. However, it should still be studied how these systems interact on the action of neurotropin and whether it acts on diseased animals such as some hyperalgesic or chronicstressed animals via the same mechanism.

\section{References}

1 Kita, T., Hata, T. and Yoneda, R.: Analgesic effect of neurotropin in mice, and comparison between analgesic effects of some drugs in SART-stressed mice and normal mice. Folia Pharmacol. Japon. 72, 573-584 (1976) (Abs. in English)

2 Takahashi, H., Shibata, M., Okubo, T., Saito, K. and Inoki, R.: Effect of neurotropin on hyperalgesia induced by prostaglandin $E_{2}$, naloxone, melatonin and dark condition in mice. Japan. J. Pharmacol. 43, 441-444 (1987)

3 Hata, T., Kita, T., Itoh, E., Oyama, R. and Kawabata, A.: Mechanism for the analgesic effects of neurotropin. Japan. J. Pharmacol. 48, $165-173(1988)$

4 Inamori, K., Hyoda, H., Ishiko, K., Kimura, K., 
Mukai, K., Nakamura, S., Ishimaru, 0 . and Hyodo, M.: Analgesic effect of neurotropin. Kiso To Rinsho 10, 2565-2570 (1976) (in Japanese)

5 Ono, K., Inoue, A., Hamada, H. and Ogawa, N.: Clinical evaluation of neurotropin tablet (NT) on low back pain-double-blind study in comparison with placebo using ibuprofen tablet as a basic treatment. Japan. Pharmacol. Ther. 10, 5813-5832 (1982) (in Japanese)

6 Motomura, K., Mabuchi, K., Chinzei, T., Abe, Y., Fujimasa, I., Atsumi, K. and Toyoizumi, Y.: Thermographic evaluation of therapeutic effect of neurotropin special for orthopedic pain. Biomedical Thermography 5, 49-52 (1985) (Abs. in English)

7 Sobue, I., Hanakago, R., Matsumoto, A., Takahashi, A., Murakami, N., Nishitani, H., Ohmura, I., I washita, H., Igata, A and Ogawa, N.: Double blind study on effects of Neurotropin on sequelae of SMON (subacute myelo-opticoneuropathy). Igaku No Ayumi 143, 233-252 (1987) (in Japanese)

8 Piercey, M.F., Dobry, P.J.K., Schroeder, L.A. and Einspahr, F.J.: Behavioral evidence that substance $P$ may be a spinal cord sensory neurotransmitter. Brain Res. 210, 407-412 (1981)

9 Hylden, J.L.K. and Wilcox, G.L.: Intrathecal substance $P$ elicits a caudally-directed biting and scratching behavior in mice. Brain Res. 217 , 212-215 (1981)

10 Kuraishi, Y., Harada, Y., Aratani, S., Satoh, M. and Takagi, H.: Separate involvement of the spinal noradrenergic and serotonergic systems in morphine analgesia: the differences in mechanical and thermal analgesic test. Brain Res. 273, 245-252 (1983)

11 Ueda, H., Amano, H., Shiomi, H. and Takagi, H.: Comparison of the analgesic effects of various opioid peptides by a newly devised intracisternal injection technique in conscious mice. Eur. I. Pharmacol. 56, 265-268 (1979)

12 Hylden, J.L.K. and Wilcox, G.L.: Intrathecal morphine in mice: a new technique. Eur. J. Pharmacol. 67, 313-316 (1980)

13 D'Amour, F.E. and Smith, D.L.: A method for determining loss of pain sensation. J. Pharmacol. Exp. Ther. 72, 74-79 (1941)

14 Zorn, S. and Enna, S.J.: The effect of mouse spinal cord transection on the antinociceptive response to the $\gamma$-aminobutyric acid agonists THIP $\quad(4,5,6,7$-tetrahydroisoxazolo $[5,4-c]$ pyridine-3-ol) and baclofen. Brain Res. 338, 380383 (1985)

15 Hata, T., Itoh, E., Oyama, R., Kawabata, A. and Kita, T.: Subsensitivity to substance $P$ in SARTstressed mice. Japan. J. Pharmacol. 49, 293296 (1989)

16 Satoh, $M$. and Takagi, H.: Enhancement by morphine of the central descending inhibitory influence on spinal sensory transmission. Eur. J. Pharmacol. 14, 60-65 (1971)

17 Levine, J.D., Lane, S.R., Gordon, N.C. and Fields, H.L.: A spinal opioid synapse mediates the interaction of spinal and brainstem sites in morphine analgesia. Brain Res. 236, 85-91 (1982)

18 Fleetwood-Walker, S., Mitchell, R., Hope, P.J., Molony, $V$. and Iggo, A.: An $\alpha_{2}$ receptor mediates the selective inhibition by noradrenaline of nociceptive responses of identified dorsal horn neurons. Brain Res. 334, $243-254$ (1985)

19 Dewey, W.L., Snyder, J.W., Harris, L.S. and Howes, J.F.: The effect of narcotics and narcotic antagonists on the tail-flick response in spinal mice. J. Pharm. Pharmacol. 21, 548-550 (1969)

20 Spaulding, T.C., Venafro, M.G.M. and Fielding, S.: The dissociation of the antinociceptive effect of clonidine from supraspinal structures. Neuropharmacology 18, 103-105 (1979)

21 Kuraishi, Y., Hirota, N., Sato, Y., Hino, Y., Satoh, M. and Takagi, H.: Evidence that substance $P$ and somatostatin transmit separate information related to pain in the spinal dorsal horn. Brain Res. 325, 294-298 (1985) 